\title{
Contextualizing communities in an instructional improvement initiative: exploring STEM faculty engagement in teaching-related conversations
}

\author{
Ellen Marie Aster $^{1 *}$ D, Jana Bouwma-Gearhart ${ }^{2}$ and Kathleen Quardokus Fisher ${ }^{3}$
}

\begin{abstract}
A frequently cited strategy for fostering science, technology, engineering, and mathematics (STEM) instructional improvements is creating communities where faculty can share and learn evidence-based teaching practices. Despite research-documented benefits, little is known about why (and with whom) faculty engage in teachingrelated conversations, including those fostered by initiative communities. We explored how STEM faculty engage in teaching-related conversations, via analysis of faculty interviews and discussion networks, to identify factors potentially influencing teaching-related conversations over the life of an initiative. Our results suggest aspects that might inhibit STEM faculty from engaging in teaching-related conversations, including: 1) faculty members' autonomy with teaching practices; 2) faculty members' varied interests in teaching improvements; 3) varied degrees of support to engage in teaching-related conversations; and 4) a lack of inclusive and non-judgmental spaces to talk about teaching. We suggest that those fostering STEM faculty communities consider working with others across the institution to map the instructional improvement opportunities faculty may already take part in and attend to areas lacking support. Initiative leaders and designers should also elicit and build off faculty members' teaching-related knowledge and concerns. We further suggest making conversational spaces inclusive and safe, to help faculty honestly share teaching-related challenges and insights. We recommend creating and fostering spaces that bring faculty together across department boundaries. Our study echoes prior research by drawing attention to administrative support for instructional improvement initiatives, which can foster and sustain opportunities for faculty to talk about teaching and learn instructional improvements.
\end{abstract}

Keywords: Postsecondary STEM education, Instructional improvement initiatives, Faculty communities

\section{Introduction}

Education researchers have called for improvements to STEM education at institutions of higher education, towards: a) better supporting undergraduate students' learning of STEM concepts and skills; b) making STEM learning environments more accessible and inclusive to diverse undergraduate students; and c) creating more STEM professionals by increasing STEM credential

\footnotetext{
* Correspondence: astere@colostate.edu

${ }^{1}$ Colorado State University, Fort Collins, USA

Full list of author information is available at the end of the article
}

holders (National Academies of Sciences, Engineering, and Medicine, 2018). In response to these charges, many institutions of higher education seek to increase the number of faculty who understand and incorporate evidence-based instructional practices. Evidence-based instructional practices consist of teaching techniques (e.g., engaging students in collaborative activities, conducting formative assessments on students' learning, and providing research experiences) which the literature has shown helps students learn. 
STEM education improvement initiatives are numerous, differing in their strategies and underlying frameworks for improving teaching and learning. In a review of nearly 200 research articles on STEM improvement efforts at institutions of higher education, Henderson, Beach, and Finkelstein (2011) found that change strategies differ in terms of the outcomes they seek to create and the aspects they seek to change. Specifically, some initiatives intend prescribed outcomes, for example via 'top-down' policies to promote/enforce teaching changes or disseminating novel teaching techniques for educators to 'take up.' Other initiatives aspire to emergent outcomes, where leaders use educators' knowledge to inform the purpose, goal, and/or vision of the initiative. Initiatives also focus on changing different aspects of the system: Some initiatives seek to change the environment or structures educators work with while other initiatives seek to enhance educators' teaching-related knowledge and/or beliefs.

One frequently cited tactic for changing educators' teaching-related beliefs is engaging educators in 'learning communities' (Bouwma-Gearhart, 2012c; BouwmaGearhart \& Adumat, 2011; Bouwma-Gearhart, Perry, \& Presley, 2014; 2012; Henderson et al., 2011), 'faculty development networks' (National Academies of Sciences, Engineering, and Medicine, 2016), or 'faculty teams' (Gast, Schildkamp, \& van der Veen, 2017). This type of change strategy, which we broadly refer to as 'faculty communities,' focuses on creating opportunities for educators to collaboratively learn and "use their own knowledge/experience/skill to improve their instructional practices" (Henderson et al., 2011, p. 962). It is argued that creating opportunities for educators to connect will help them expand their teaching-related knowledge and change their teaching practices.

In fact, previous research has suggested that creating opportunities for STEM faculty to connect confers a variety of benefits. Fostering communities creates vital spaces for educators to share pedagogical techniques and perspectives (Coldron \& Smith, 1999; Gast et al., 2017) and can foster changes to faculty members' pedagogical knowledge, teaching approaches, and teaching identity (Gast et al., 2017). Creating opportunities for STEM faculty to specifically connect with administrators can help create more 'congruent' units (e.g., departments, schools), where administrators and faculty share beliefs about teaching (Wright, 2008). Additionally, creating opportunities for STEM educators to connect with others has been shown to motivate faculty in large-scale (e.g., national) change initiatives "to continue to reform in the face of departments and institutions that may not be supportive" (Kezar, Gehrke, \& Bernstein-Sierra, 2017, p. 232).

However, despite the prevalence of faculty communities as a change strategy and research-documented benefits, relatively little is known about how STEM faculty generally engage in teaching improvement activities (Bouwma-Gearhart, 2008). What brings these faculty to the table? What keeps them there? And what do they find meaningful? We know less about their teachingrelated conversations specifically, including why and with whom they engage. In particular, STEM faculty engagement in teaching-related conversations at institutions undergoing instructional improvement initiatives is an emerging area of study. Such studies can help diagnose the need for instructional improvement efforts and guide the design and implementation of improvements in light of the complex professional contexts of faculty (Bouwma-Gearhart, Sitomer, Fisher, Smith, \& Koretsky, 2016; Bouwma-Gearhart, Ivanovitch, Aster, \& Bouwma, 2018).

Our exploratory study investigates STEM faculty engagement in teaching-related conversations, including during an ongoing instructional improvement initiative. We combine survey-based social network analysis with analysis of STEM faculty interviews to explore the changes to teaching-related discussion networks over the life of an initiative as well as identify factors potentially influencing STEM faculty engagement in teachingrelated conversations. Our results have implications for stakeholders promoting and involved in the construction of communities, where faculty have the opportunity to collaboratively learn about teaching and instructional improvements.

\section{Theoretical perspective}

We employ second-generation cultural-historical activity theory (Engeström, 2009; Leont'ev, 1981), which orients our analysis to the 'activity' of teaching-related conversations. Activities are collective actions shaped and defined by the multivoicedness of those involved (Engeström, 2009; Foot, 2014). Activities are also shaped by culture, in that all human actions are affected by "cultural values and resources," as well as history, since "cultures are grounded in histories, and evolve over time" (Foot, 2014, p. 3). We employ second-generation cultural-historical activity theory as a heuristic tool for identifying factors potentially impacting STEM faculty engagement in teaching-related conversations and for interpreting an initiative's influence on teaching-related conversations.

The heart of second-generation cultural-historical activity theory is the activity system (Engeström, 2014). Activity systems have six interacting components that shape the activity (Fig. 1). Subjects, or the actors engaged in the activity, utilize tools to facilitate action towards the object of the activity system. The object can be described by different facets: It is "a thing-to-beacted-upon," an objectified motive (which describes why the object is interacted with), and a desired outcome 


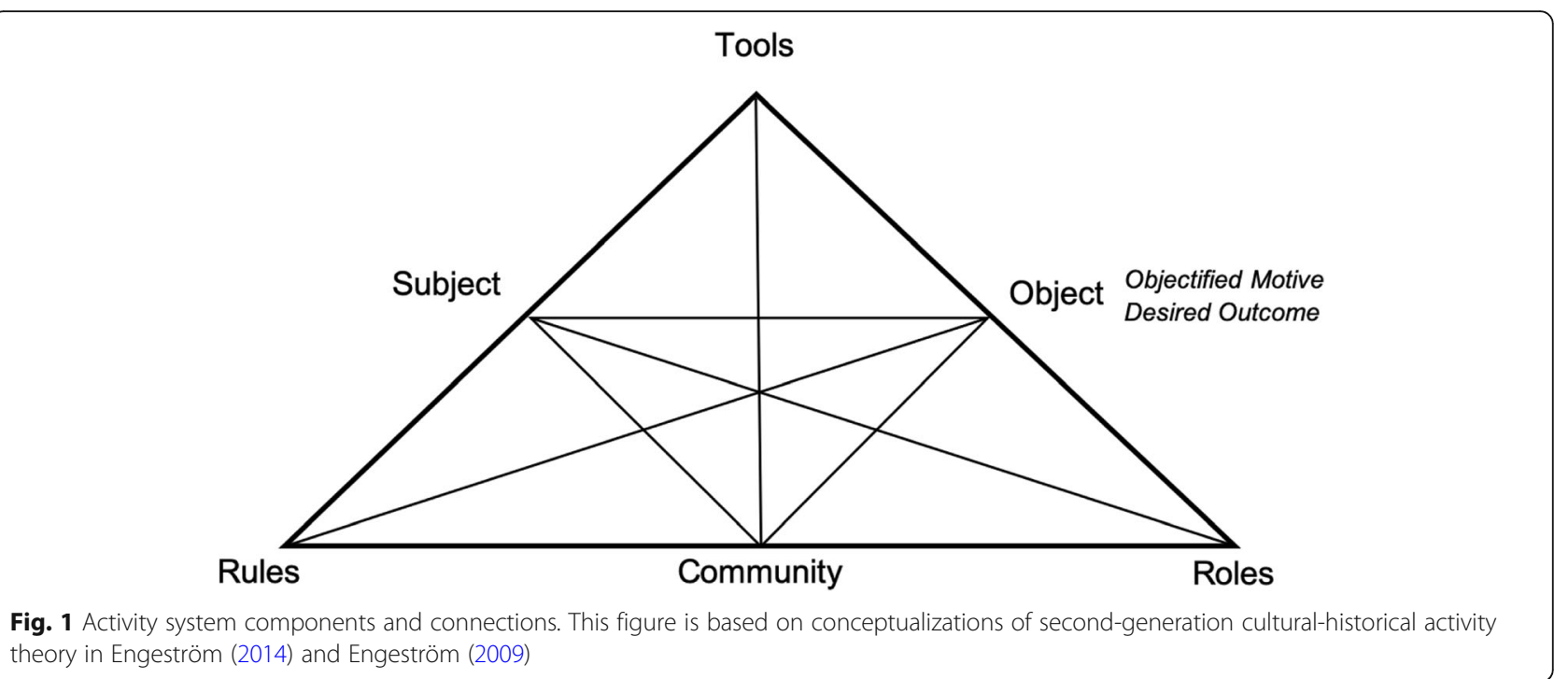

(which describes the intent from interacting with the object) (Foot, 2014, p. 10). For example, a STEM faculty member (i.e., a subject) might use Skype (i.e., a tool) to talk with colleagues to align content between courses (i.e., the desired outcome). The community of an activity system consists of the people who "share with the subject an interest in and involvement with the same object" (Foot, 2014, p. 6). For example, STEM faculty work with others in an institution of higher education, including administrators, faculty of various positions (e.g., associate professors, assistant professors, professors, and instructors), and students (e.g., undergraduate and graduate students). These community members have the potential to shape the 'activity' of teaching-related conversations, since they may have different motivations to engage in teaching-related conversations.

Rules also shape action within an activity system. For example, STEM faculty may believe it is part of their job to publish and communicate disciplinary research but not part of their job to talk with others about teaching. This 'rule' might stem from official promotion and tenure guidelines that place an emphasis on research over teaching. It might also be more implicit, such as faculty perceiving that engaging in teaching-related conversations is out of the norm and, thus, should be a limited activity. Work is also divided differently among community members, resulting in a division of labor or different roles. For example, tenure-track STEM faculty might be expected to conduct discipline-specific research whereas tenure ineligible (e.g., fixed-term or instructional) faculty might be expected to deliver more teaching. Faculty who are assigned more teaching responsibilities may engage in more teaching-related conversations, since teaching is a larger portion of their formal position descriptions.
In an activity system, contradictions or tensions can occur when components, such rules and roles, are at odds (Engeström, 2014). For example, both tenure-track and fixed-term STEM faculty might want to engage in teaching-related conversations, but a department 'rule' excludes fixed-term faculty from meetings where teaching policies are discussed. Identifying contradictions provides opportunities to address tensions inhibiting activity (Foot, 2014). Cultural-historical activity theory helps us consider the components of the activity system that have the potential to influence faculty connections with community members in the 'activity' of teaching-related conversations -- and how those conversations might be affected by an institution-wide, instructional improvement initiative. When we locate possible tensions in the activity system, we can suggest improvements to support faculty members' engagement in teaching-related conversations.

\section{Methods}

\section{Research questions}

Our research is guided by the question, How do STEM faculty engage in teaching-related conversations within the context of an institution of higher education with an ongoing instructional improvement initiative? We explore the following three subquestions:

1. Why do STEM faculty, at an institution of higher education, engage with community members around teaching-related topics? What components of the activity system potentially influence STEM faculty engagement in the 'activity' of talking about teaching-related topics?

2. How has an instructional improvement initiative influenced STEM faculty engagement in teaching- 
related conversations? How has an initiative influenced STEM faculty engagement in the 'activity' of talking about teaching-related topics?

3. How have STEM faculty networks, wherein faculty discuss teaching-related topics with community members, changed over the life of an initiative?

\section{Participant sample and research setting}

The participants in this study were fourteen STEM faculty working at an institution of higher education classified as a doctoral university with the highest research activity (Carnegie Classification of Institutions of Higher Education, n.d.). The data in this paper are part of a larger, Institutional Review Board (IRB)-approved study to research and evaluate an instructional improvement initiative, which aimed to improve teaching in largeenrollment, first- and second-year STEM courses in seven units (i.e., departments or schools) across two colleges. For this paper, we use data from interviews with STEM faculty, concerning their teaching experiences and perceptions, as well as data from two social network surveys concerning STEM faculty members' conversations about teaching-related topics. Data from the fourteen STEM faculty who completed both interviews and two social network surveys (early- and late-project) form the basis for this study. Participants worked in both colleges and five of the seven units targeted by the initiative.

The initiative, which began in early 2014, intended to foster instructional changes by leveraging the distributed expertise of faculty across targeted STEM units. This included supporting and creating communities, both within and between units, where STEM faculty could share and learn evidence-based instructional practices. Evidencebased instructional practices encouraged by the initiative included interactive student engagement, student collaboration and cooperative learning, and frequent formative feedback to inform students' learning and instruction. Faculty were also encouraged to propose topics of interest in initiative-supported activities. Communities supported by the initiative included: a) an elective practitioner inquiry program, where STEM faculty conducted small scale (i.e., classroom-based) research projects to inform teaching improvements; b) a learning assistant program, where undergraduate students learned pedagogy and applied that understanding to help peers learn STEM concepts; c) larger socials three times a year, open to all faculty, to discuss and learn relevant teaching-related topics; and d) regular meetings between initiative designers/leaders and unit faculty. Table 1 lists participants' pseudonyms, professional

Table 1 List of Participants, Participants' Professional Positions, and Participants' Involvement in the Initiative

\begin{tabular}{|c|c|c|c|c|}
\hline \multirow[t]{2}{*}{ Participant } & \multirow{2}{*}{$\begin{array}{l}\text { Professional } \\
\text { Position }\end{array}$} & \multicolumn{3}{|l|}{ Initiative Involvement } \\
\hline & & Initiative planner/implementer & Attended initiativerelated event(s) & Little to no involvement \\
\hline \multicolumn{5}{|l|}{ Unit A } \\
\hline Avery & Tenure Track Faculty & $x$ & $x$ & \\
\hline Alexis & Fixed-Term Faculty & & $x$ & \\
\hline \multicolumn{5}{|l|}{ Unit B } \\
\hline Blake & Tenure Track Faculty & $x$ & & \\
\hline Blair & Fixed-Term Faculty & $x$ & & \\
\hline Bowie & Fixed-Term Faculty & & $x$ & $x$ \\
\hline Briar & Fixed-Term Faculty & & $x$ & \\
\hline \multicolumn{5}{|l|}{ Unit C } \\
\hline Charlie & Fixed-Term Faculty & $x$ & $x$ & \\
\hline \multicolumn{5}{|l|}{ Unit D } \\
\hline Dallas & Fixed-Term Faculty & $x$ & & \\
\hline Dakota & Fixed-Term Faculty & $x$ & & \\
\hline Drew & Tenure Track Faculty & & $x$ & \\
\hline Dana & Tenure Track Faculty & & & $x$ \\
\hline Dane & Fixed-Term Faculty & & & $x$ \\
\hline \multicolumn{5}{|l|}{ Unit E } \\
\hline Ellery & Tenure Track Faculty & & $x$ & \\
\hline Elliott & Tenure Track Faculty & & & $x$ \\
\hline
\end{tabular}

Note. We specifically use gender-neutral pseudonyms, since gender is not a construct explicitly explored in this study and we do not want to assume participants' gender identities 
positions, and the level of involvement they indicated they had in the initiative.

\section{Data collection}

We collected both interview and survey data from STEM faculty participants. Interviews helped us explore why faculty engage in teaching-related conversations as well as how an initiative influenced engagement in teachingrelated conversations. Survey data helped us understand with whom faculty talk about teaching and how this structure of ties (or social network) changed over time. Combined, these two methods generate an "understanding of how networks matter" and "what mechanisms and conditions figure in when producing certain network outcomes" (Hollstein, 2011, p. 408).

\section{Interviews}

We developed a semi-structured interview protocol to understand STEM faculty members' professional lives related to teaching and the initiative. When determining which faculty to invite to interviews, we considered participation in initiative-related opportunities, participation in other on-campus, evidence-based instructional events, and involvement in unit teaching-related decisions. Nineteen of twenty-one invitees consented to interviews (90\% response rate). Staff from a research corporation conducted interviews in the spring of 2017, approximately 3 years after the initiative was implemented.

\section{Surveys}

STEM faculty (administrators, tenure-track faculty, and fixed-term faculty) who worked in units targeted by the initiative were identified via unit webpages and sent an invitation to participate in a five-scale survey ${ }^{1}$ asking questions related to their teaching profession. This included a social network section. A small amount of previous research suggests the usefulness of social network analysis for understanding STEM faculty members' discussion of teaching-related topics. For example, social network analysis can suggest how teaching-related ideas spread through STEM units targeted by improvement initiatives (Henderson et al., 2018) and can show with whom STEM faculty talk, towards identifying potential leaders of change efforts (Quardokus \& Henderson, 2015; Knaub, Henderson, \& Quardokus Fisher, 2018). Furthermore, social network analysis can show what teaching-related topics STEM faculty of different professional positions talk about (Quardokus Fisher, Sitomer, Bouwma-Gearhart, \& Koretsky, 2019).

\footnotetext{
${ }^{1}$ The first survey also invited three postdocs from one department, because they were instructors of record for lower-division STEM courses.
}

The first survey was completed in the fall of 2014, shortly after the initiative was first funded. The second survey was completed in the spring of 2017, approximately 3 years after the initiative started. The 2014 survey was completed by 141 of 262 faculty (response rate of $54 \%)^{2}$ and the 2017 survey was completed by 123 of 329 faculty $^{3}$ (response rate of $37 \%$ ). We used the data from the social network sections of these surveys, which asked faculty to list up to 10 people with whom they talk (hereafter referred to as 'discussion partners') about teaching-related topics, with follow-up questions about discussion partners and the nature of these conversations.

\section{Data analysis}

Interview and social network data were analyzed in iterations, allowing comparison of emerging inferences from the social network data and themes, or codes, from interview transcripts. The authors met regularly to discuss analyses, brainstorming how each set of data offered information on how participants engaged in teaching-related conversations.

\section{Interview Analysis}

To understand why STEM faculty engage with community members around teaching-related topics, the first author coded transcripts using the open coding methods described in Auerbach and Silverstein (2003). The first author shared emergent codes with the other authors for comments and edits. This peer debriefing allowed checking of codes, towards adding validity to the findings (Creswell, 2014). The first author conducted a second round of coding using the Dedoose analysis platform. Rereading interview transcripts and, keeping in mind the emergent codes constructed during the first round of coding, textual excerpts were re-sorted and grouped under previous codes. Codes were amended and new codes were created, as needed. Coauthors again discussed and resolved differing interpretations of codes. Finalized codes were considered in light of culturalhistorical activity theory via memos and coauthor discussions. This illuminated how codes related to the components (i.e., rules, etc.) of second-generation cultural-historical activity theory. Cultural-historical activity theory was used as a heuristic tool to organize results and explore how activity system components (e.g.,

\footnotetext{
${ }^{2}$ This count does not include the three postdocs, two of whom completed a 2014 survey and one who was invited, but did not complete, a 2014 survey.

${ }^{3}$ In total, 129 surveys were completed in 2017. However, two surveys were not identifiable (i.e., participants indicated no affiliated unit and did not identify themselves) and three surveys were completed by a faculty member who had already completed a survey. Additionally, one survey was completed by a postdoc, and thus removed from this study.
} 
rules) potentially influence teaching-related conversations.

The final codebook included code names, definitions, and excerpts used to build and define codes. Three main decisions regarding what excerpts to include in the final codebook narrowed the focus to answer the research questions. First, excerpts related to teaching undergraduates, such as giving formative or summative feedback or helping students during office hours, were not included. While these activities might broadly constitute 'engaging in teaching-related conversations,' we dubbed them more akin to instructional tasks and, therefore, less useful in capturing how faculty talk about teaching-related topics, including instructional improvements, with community members. Second, participant comments about attending meetings, events, professional development opportunities, etc. were not included, unless participants explicitly stated or implied that these events served as opportunities to communicate with others around teaching-related topics. This is because some instructional improvement events may have sought more prescribed outcomes, for example via top-down dissemination of curriculum and pedagogy, and thus not have been spaces where faculty discussed teaching-related practices and beliefs. Third, excerpts where participants mentioned ways the initiative influenced teaching-related conversations were only included. In other words, we did not include participant perspectives about how the initiative generally impacted them professionally or personally, unless these impacts related to our focus on engagement in teachingrelated conversations.

\section{Social Network Analysis}

Social network responses from the 2014 and 2017 surveys were analyzed to understand how STEM faculty networks, representing discussions about teachingrelated topics with community members, changed over the life of an initiative. We first created ego network sociograms using the 2017 and 2014 social network responses. Ego networks focus our analysis on the set of actors (i.e., STEM faculty) and the ties among them (i.e., the connections that represent teaching-related discussions) (Prell, 2012). Ego network actors only include faculty who were invited to take the survey, since we cannot make assumptions about network connections for those not invited. ${ }^{4}$ That said, we noted one person who was not invited to complete a 2014 survey but who was still identified by five faculty as someone with whom they discuss teaching-related topics. Given the frequency

\footnotetext{
${ }^{4}$ For example, we cannot make assumptions about network connections to faculty members' partners or faculty at other institutions, since these people were not invited to complete a social network survey.
}

with which this person was mentioned, we decided to include this person in our networks. In summation, our 2014 and 2017 ego networks include: 1) the fourteen faculty participants; 2) with whom participants reported talking about teaching and learning at this institution; 3 ) other faculty (participants of the larger study and evaluation of the initiative) who spoke with one or more of our fourteen participants; and 4) the relevant ties between these community members.

We assumed nondirectional ties between faculty and we represented a reported tie with a value of ' 1 ' and the absence of a tie with a value of '0.' Metrics are affected by network size and response rate, so we compared the 2014 and 2017 networks. We found that the two networks were similar in size: The 2014 network included 58 faculty and the 2017 network included 50 faculty. The response rates were also relatively similar: The 2014 network had a response rate of $86 \%$ and the 2017 network had a response rate of $78 \%$. While $100 \%$ response rate is obviously preferred, around $80 \%$ response rate is the conventional 'low bar' for social network analysis (Henderson et al., 2018) and our networks are around this value. Due to the relatively close size of the networks and the reasonably high response rates, we determined that it was appropriate to compare the networks. However, size and response rate are still considered in our interpretation of results.

To understand how STEM faculty networks changed over the life of an initiative, we compared the 2014 and the 2017 networks. First, we looked for changes in network cohesiveness, or changes in the interconnectedness of the networks. Networks that are more cohesive are more likely to have a shared understanding of teachingrelated topics (Quardokus \& Henderson, 2015). Per Prell's (2012) recommendation, we calculated four metrics of network cohesiveness: density, centralization, diameter, and average distance (heretofore referred to as 'average path length'). Each metric provides a slightly different interpretation of interconnectedness. Density describes how many ties a network has compared to all possible ties. A high density score (maximum of ' 1 ') represents a more cohesive network and a low density score (minimum of ' 0 ') represents a less cohesive network. Centralization is a measure of the "extent to which one actor in a network is holding all the ties in that network" (Prell, 2012, p. 169). A network with a low centralization score has more equally distributed ties between faculty while a network with a high centralization score has ties mostly connected to one or a few faculty member(s). Next, we calculated average path length and diameter (Wasserman \& Faust, 1994). Path length represents the number of ties by which two actors are separated. Average path length represents the average of the shortest path lengths between all pairs of actors. Diameter is 
similar to path length and average path length: It reports the longest of the shortest path lengths between any pairs of actors. We calculated each of these cohesiveness metrics for the 2014 and 2017 networks so we could compare the cohesiveness over time, or compare the extent faculty talked with others about teaching-related topics in 2014 and 2017. A network with consistent interpretations of cohesiveness across the four metrics suggests greater cohesiveness than one with inconsistent interpretations of cohesiveness across metrics.

We also compared the types of faculty ties for each participant, to explore changes in intra- and extra-unit discussion partners. Specifically, we counted the number of ties each participant had to faculty within their unit and outside of their unit in 2014 and 2017. Combined with the cohesiveness calculations, these analyses helped us interpret the extent participants' discussion partners (with whom they talk about teaching) changed over the life of an initiative.

\section{Limitations}

We note limitations that define the boundaries of our research, towards inspiring future studies to contribute to a more comprehensive understanding of STEM faculty engagement in teaching-related conversations and instructional improvement efforts. First, a limitation of the social network data is that some participants reported talking to partners or others outside of the institution, but these discussions are not incorporated into our networks because extra-institutional discussion partners did not participate in our study and because our focus is on STEM faculty engagement in conversations in the context of an institution of higher education. Future research could illuminate the larger landscape of faculty conversations concerning teaching, including those potentially happening at disciplinary conferences, in national professional development workshops, and with family. Our exploratory study also took place at one institution with one improvement initiative targeting a limited number of STEM disciplines. Future research may want to compare faculty experiences across institutions and initiatives to better diagnose the factors influencing faculty engagement in teaching-related conversations.

Additionally, we have more fixed-term than tenuretrack faculty participants in our study. This was, in part, due to our criteria for participants who were involved in the initiative that explicitly targeted courses that fixedterm faculty most often teach at this institution, those being large-enrollment, first- and second-year STEM courses. We acknowledge that our study proportion of fixed-term to tenure track faculty may not be representative of STEM units, colleges, and the institution. Future research might compare the experiences of tenure-track and fixed-term faculty in instructional improvement initiatives and professional development opportunities, particularly those targeting involvement of faculty of different professional positions.

Last, the authors helped with the design of the initiative based on research data, with the third author specifically leading some initiative activities. While some may consider it a bias threat to work so closely with an initiative, we argue that this insider perspective gives vital, in-depth knowledge about the initiative and the participants targeted by the initiative. To adequately understand how an initiative is planned and implemented, as well as the experiences of those engaged in it, researchers may not have the luxury of being 'entirely removed' from influencing it.

\section{Results}

We first present results related to our first two research subquestions, which were informed by analysis of interviews with STEM faculty. We then present results for our third research subquestion, which was informed by social network analysis.

\section{Why Do Faculty Talk About Teaching-Related Topics?}

Analysis of interviews with STEM faculty revealed factors that have the potential to shape the activity of teaching-related conversations at an institution of higher education (Fig. 2). Participants suggested that an objective of engaging in teaching-related conversations was to compare teaching practices as well as find support in comfortable and safe conversations. For example, Alexis explained that talking to faculty about teaching-related practices has been "one of the most fruitful things because we look at how the other person delivers something and we say why did you deliver it that way, I would have delivered it this way, and we have conversations that illuminate different ways to think about the delivery of content." Ellery found that this support created a "space for people to feel comfortable reflecting on their teaching." This suggests that faculty may be inclined to engage in teaching-related conversations to learn about a variety of teaching approaches within supportive spaces.

Participants spoke of 'tools,' or opportunities to converse with others about teaching-related topics. These included organized events inside the institution (e.g., through the teaching and learning center) and events specifically related to their STEM program and/or unit (e.g., collaborating with others around unit courses). Participants also spoke of opportunities outside of the institution where teaching-related topics have the potential of being discussed, such as conferences or in professional organizations. Participants additionally discussed opportunities more difficult to locate with 


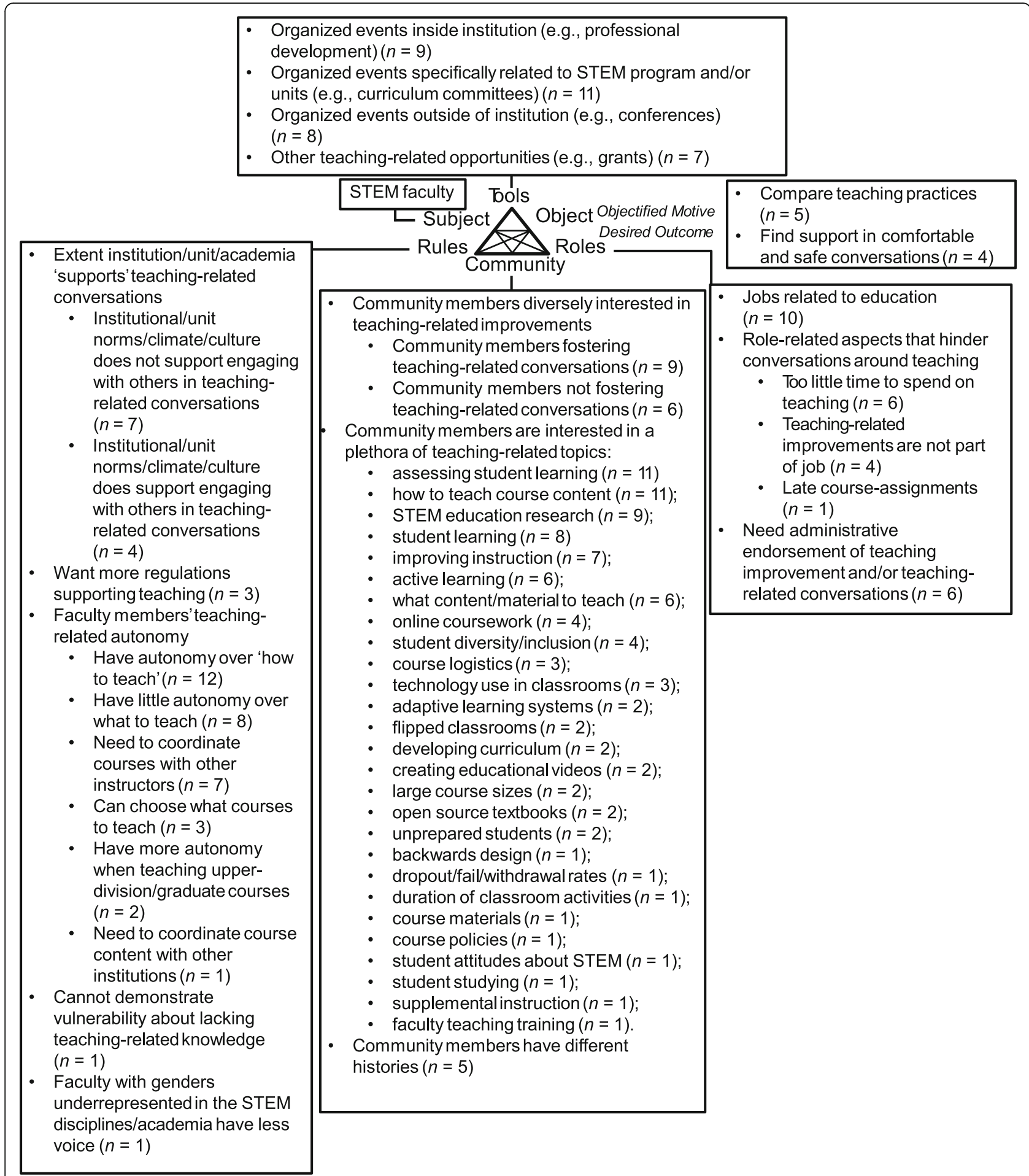

Fig. 2 The components of the activity system that potentially influence STEM faculty engagement in the activity of talking about teaching-related topics. The number of participants who contributed interview excerpts to each code is given by $n$

respect to the institution, where teaching-related topics might be discussed (e.g., education-related grant work). This suggests faculty may use or have access to a vast array of opportunities where they engage in teaching- related conversations and, potentially, learn about instructional improvements.

Participants also suggested 'rules' that might influence engagement in teaching-related conversations, including 
the extent the institution, unit, and/or academia supported talking about teaching with colleagues. For example, Charlie noted there being an "element of like we don't talk about our teaching at the higher ed, it's just something that we do. We don't necessarily talk about that at our faculty meetings." Blair offered a different perspective, describing an "overall picture [in their unit]" that faculty engage in best teaching practices and teaching improvements. While these views seem to be at odds with each other, Alexis provided an explanation for the variability:

...depends on what [unit] and what [institution] you're in as to what sort of motivations you have to have these kinds of conversations to make these kinds of changes. [This institution] in general, and I don't have a lot to compare it to, I think is very supportive in improving education and getting together having conversations and spending some of your time actually thinking carefully about how you teach and how you could improve on that, but you see some variability inside different [units].

Some participants indicated wanting more regulations, or policies, supporting teaching improvements and related conversations. For example, Charlie noted that they were busy and thought that a more cohesive, institutional vision regarding instructional improvement initiatives might help them use their time more effectively:

[W] e've got all these things and all these different people are working on it, but it's almost like we're not focused enough to really figure out what it is we really want to do. So I feel like there needs to be some sort of master plan about all these education initiatives and that kind of includes [this initiative] and how we think about where we as an institution are and how we as an institution move forward and I feel like a lot of it hasn't been an institutional think tank, it's been kind of from the bottom up, which has value, but I think at some point we've got to get to that institutional level think tank where we can make some sense of all this stuff. Honestly, I have a lot on my plate and sometimes it's just overwhelming.

Participants also talked about the varying degrees of autonomy they have with teaching-related tasks, which has potential to shape teaching-related conversations since areas of less autonomy may necessitate collaboration. Almost all participants spoke about having autonomy over how to teach, like Blake who explained, " $[\mathrm{H}]$ ow and what we teach is fairly decided [by] us, the instructors." Many participants also described little autonomy over what they teach (e.g., course content). As Blair explained:

[With the introductory courses], not much [autonomy] for the curriculum. We have content curriculum to cover, our preparation for students continuing in the [STEM disciplines], understanding key physical concepts, pretty much dictates the curriculum.

Relatedly, participants spoke about needing to coordinate course curriculum with other instructors. For example, when asked how much autonomy they have over what they teach and how they teach, Avery explained:

So basically what I teach very little [autonomy], because we discuss this and we have a lower division curriculum group that meets every 3 weeks and we talk about curriculum, what has to go on there, so basically we all agree on which parts go where.

Similarly, Alexis added that the curriculum they covered was constrained because a change would mean "about twelve or thirteen [institutions of higher education $\left.^{5}\right]$ that would change and shift as well [...] So in that sense I can't make much changes as to what particular topics we cover."

Some participants also indicated having autonomy over course assignments, like Drew who explained they had "flexibility in what I get to teach, yeah, lots of flexibility." A couple of participants specifically talked about having autonomy when teaching upper-division and graduate courses, such as Drew who reflected, "For the most part like upper-division courses and graduate-level courses I feel like I have a lot of autonomy in what I teach and how I teach." Collectively, these excerpts suggest that STEM faculty may have great autonomy concerning how to teach, but not necessarily what content to teach (unless, as some participants suggested, they are teaching upperdivision or graduate-level courses). Identifying areas where faculty have teaching-related autonomy helps us understand potential motivations for engaging in teachingrelated conversations, such as needing to align course content with community members.

Ellery brought up another 'rule' that has the potential to shape teaching-related conversations. Specifically, Ellery spoke at length about how STEM faculty cannot openly need help with their teaching, or how it is challenging to earnestly lack teaching-related knowledge. Ellery viewed this as an existing "value judgment that can be implicit" in talking with others about evidencebased instructional practices. "[I] t seems to me," Ellery explained, "that telling someone there's a right way to do it and you're doing it the wrong way is anathema

${ }^{5}$ Although Alexis did not clarify, they might have been speaking to local institutions which students might transfer from. 
[inaudible] interaction, and it's a hard thing to balance." They elaborated that this vulnerability might stem from a lack of recognition, across the unit, of the complexity of teaching:

I think some of the disconnect is the imposter syndrome thing [inaudible] of you're younger or somehow a lower status it's really hard to believe that anyone else is as overwhelmed as you. You just, you know, do the [inaudible] job based on your research ability and that's great and then all of a sudden you find yourself in front of like four five college students you're supposed to teach [a STEM subject] and you're like oh shit, I don't know how to do this, and it's hard to admit. So acknowledging is a really hard thing and it's important to us, so much more important that we don't have time to...You know when you ask for directions and someone is like how did you end up here, and it's like come on dude, I admit it, I'm lost, help me. I'm not going to go through all the poor decisions I made [inaudible]. So really if you're a full professor [in this discipline] and you've been doing teaching for thirty years, traditional teaching, learning after thirty years that there's a full body of literature and research that kind of exists that could've made everything better is difficult.

Ellery's excerpts suggest that some STEM faculty may not want to be vulnerable in their lack of teachingrelated knowledge: This may dissuade STEM faculty from participating in teaching-related conversations.

Dana suggested another implicit 'rule' related to gender identity and access to teaching-related conversations. Although Dana noted that they talk to other faculty about teaching-related topics, they admitted sometimes feeling dissuaded from contributing since others might not value their comments:

You have to realize too, I said I was a [tenure-track faculty member in a STEM discipline]. I have been here [a long time]. What do you think that makes me? You know, gender-wise, honestly, what do you think, okay, you know I've come into this profession and I've been an outsider. I'm not going to take something I do that's different than what other faculty members do and advertise it. I may be very successful at it, but if I advertise it there will be repercussions. I just don't want to go there anymore. I and the students know this is working really well, that's enough.

Dana's comments add further information on factors that may shape who participates in teaching-related conversations, including the extent faculty may feel able and comfortable to participate based on their identities.
Interviews also revealed community-related aspects that have the potential to influence teaching-related conversations. Specifically, participants described a diverse community, in terms of interests in teaching and making teaching improvements. Many stated or implied that engaging with people who are interested in teaching, value teaching, or want to know how to implement teaching improvements helped foster teaching-related conversations. Speaking to how teaching-related conversations benefit from intrinsically motivated faculty, Avery mused:

[Y] ou really need a group of people that themselves are interested and only when you have a critical mass there, and I think we do have a critical mass here, then more people will get on board. But if [the] administration says this is what you've got to do, people say sure, they'll do it for a little bit, then it disappears. So you really need this local interest and I think a lot of places have that, so I'm not worried about it, but if it's not there for some reason, you cannot build it by force.

Participants also mentioned community members who did not foster teaching-related conversations, such as "lecture-type people," "bullies," faculty who were perceived as having little teaching-related knowledge, and faculty who were uncollaborative. Briar summarized:

It's difficult to have those conversations with people who absolutely believe that standard lecture is the gold standard of teaching. So being open minded about different approaches is certainly encouraging it and the opposite is also true for those who are adamant that standard lecture is [...] it, it's difficult to have a conversation.

Working in a diverse community, with colleagues who are variably interested in teaching and instructional improvements, shapes teaching-related conversations. Our participants suggest that certain community members may be more open to and interested in talking about teaching than others.

Participants also suggested that the community was interested in a plethora of teaching-related topics, indicating that those interested in instructional improvements may want to engage in conversations drawing on a wide range of teaching topics (listed in detail in Fig. 2). "Need is the ultimate encouragement," explained Bowie, commenting on what motivates their conversations with others around course content. "If I don't know how to do something I have to figure out how to do it. So I'll engage resources at that point and people out here are some of my best resources." 
Participants also offered information about histories with various community members, which explained some faculty members' teaching-related conversations. For example, Avery and Elliott credited their longevity at the institution as contributing to their teaching-related connections. "There's a whole bunch of history there," Avery explained, elaborating on their previous participation in a discipline-specific teaching preparation program and how this allowed them to become more aware of how "standing in front of the classroom and talk [ing] for fifty minutes is not very effective." Elliott also mentioned working at the institution for many years, in different units: "I've interfaced real closely [with people in these different units]," Elliott explained. "I've consulted a lot. I bring a lot of that into the classroom." This suggests that longevity at the institution as well as sharing teaching-related experiences with others explains some faculty members' engagement in teaching-related conversations.

Relating to the ways roles influence teaching-related conversations, participants mentioned nine educationspecific jobs or positions they either engaged in or others held that potentially influence teaching-related conversations. For example, Dallas commented that "most of the [fixed-term faculty] are more interested in and apt to get involved" in collaborative, education-related grants since "particularly for [fixedterm faculty], we do focus on education often more than a lot of the tenure track people." Dane commented on how taking on the role of course coordinator afforded conversations, explaining, "This past year I've been the coordinator for [a STEM course] so I interact with people teaching [this course] in a particular term." A couple of faculty members also talked about how their roles as unit-wide professional development providers helped them work with faculty. For example, Charlie explained that they had "worked with faculty on their professional development, which also allows me to do my own professional development at the same time."

Other participants mentioned specific role-related duties that potentially motivate teaching-related conversations, like Bowie who meets with community members through "doing academic outreach with students." Avery mentioned that their unit hired a community member to do lower-division work who they had "interacted [with] a lot," implying that having a "separate person who's running the labs" helps foster conversations about lab needs. Elliott specifically mentioned talking with another community member about "what kinds of things work, what doesn't work" who was a "social justice leader" and commented on how the professional advancement of faculty committed to changing teaching practices encouraged teaching-related conversations. According to our participants, those in professional positions focused on education shape and potentially foster teachingrelated conversations.

Faculty also mentioned role-related aspects that hinder teaching-related conversations, such as time constraints, the perception (held by some) that engaging in teachingrelated conversations or improvements is not part of their jobs, and receiving late course assignments. Speaking to time restrictions, Bowie commented:

I don't think there's any villain out there trying to stop this [interactions with others around teachingrelated topics] from happening, so there's no evil [inaudible] preventing these things [interactions] from happening, but I think the biggest factor impeding me is my teaching schedule.

Implying that some faculty may feel that engaging in teaching-related conversations is not part of the job, Charlie succinctly stated, "I think a lot of faculty work in isolation." Finally, Drew felt discouraged to engage in teaching-related conversations due to late course assignments:

...sometimes instructors aren't assigned to teach classes, like they don't know what class they're going to teach until like a week before classes start, sometimes 2 days before classes start. So with that, like how can you have meaningful conversations about the course before the term starts.

Finally, participants spoke about how administrative endorsement of improvement efforts or teaching-related conversations could help faculty talk about teaching and, potentially, learn about instructional improvements. As Avery commented, "There is a lot of encouragement from our dean to say 'hey teaching is important' and to support those objectives." Elliott took it one step further and noted needing institutional support, or "intentional university commitment rather than thinking of it as oh, yeah, they do [this discipline-specific education] research over there, they got millions of dollars, they're fine." These excerpts suggest that administrative support could positively influence teaching-related conversations and, optimally, faculty implementation of instructional improvements.

\section{How has an Instructional Improvement Initiative Influenced Faculty Engagement in Teaching-Related Conversations?}

Interviews help us understand how the instructional improvement initiative influenced faculty engagement in teaching-related conversations (Fig. 3). Participants offered information on their objectives for participating in 


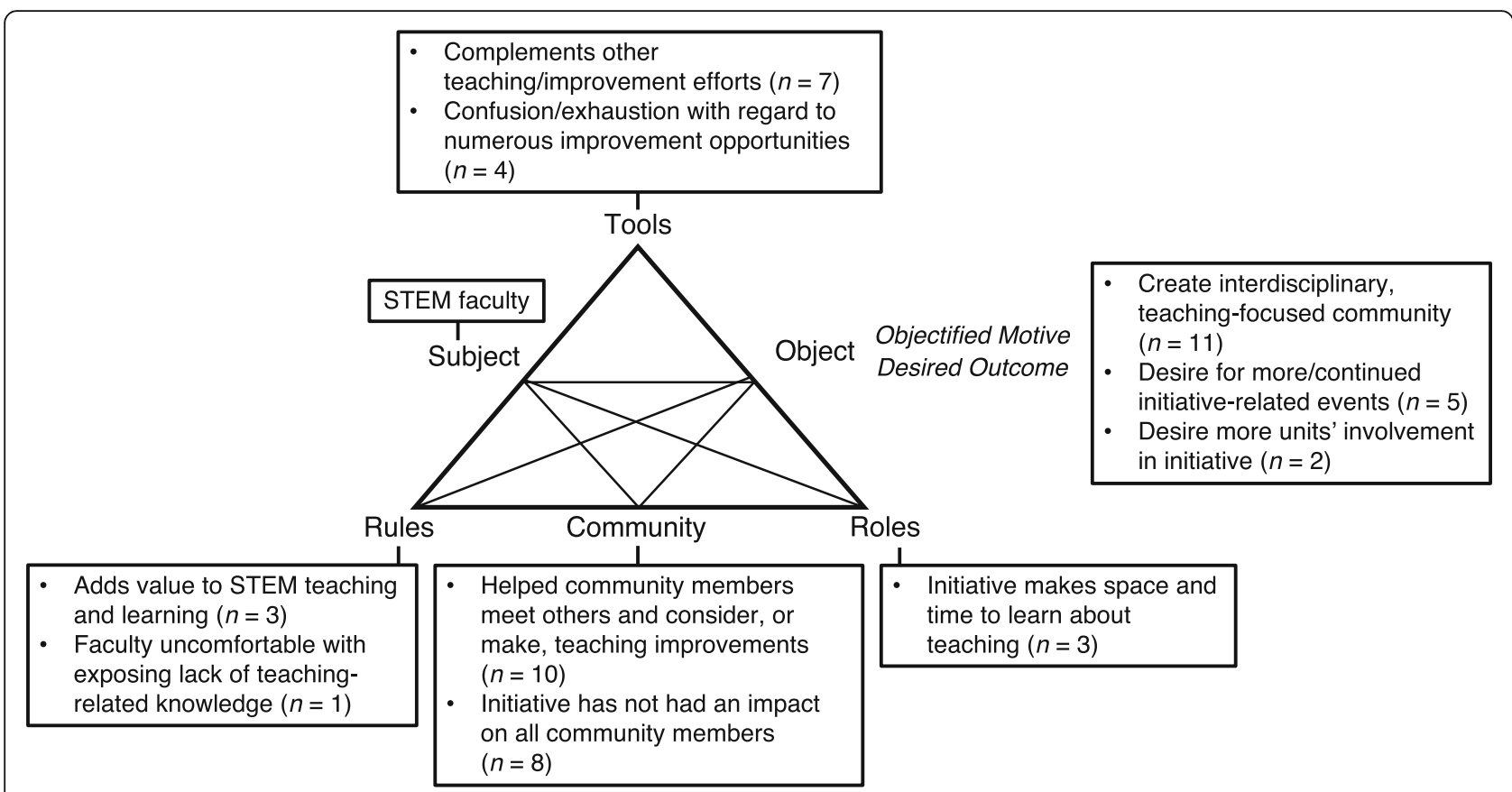

Fig. 3 Ways an instructional improvement initiative influenced STEM faculty engagement in the activity of talking about teaching-related topics. The number of participants who contributed interview excerpts for each code is given by $n$

initiative-related communities, speaking about how the initiative provided a vital opportunity to connect with interdisciplinary community members at the institution who were interested in education. "I really enjoy getting to know faculty outside my unit," commented Charlie. "That's been really great with [this initiative]." Similarly, Blake commented:

I certainly did meet new people or get a closer working relationship with a few people through the project and that certainly were here for a long time, so that gives us new people to talk to and perhaps collaborate with, perhaps write grants with, perhaps discuss things with. So that was another good thing.

Participants also spoke about wanting more initiativerelated events, continued initiative-related events, and more units' involvement in the initiative. "My biggest suggestion," Dallas offered, "is more opportunities to just get together and talk about and share ideas about teaching and learning with other people in the [initiative]." Avery worried how the end of the initiative might affect these new connections: "Without [the initiative,] how are different [units], are they going to get isolated again, or keep working together, what can we do to keep that momentum going...." A couple of participants also spoke about wanting the initiative to include more units, such as Charlie who explained that "there are certainly a whole lot of other units out there that could benefit from participation in something like this." Talking about teaching with multi-unit community members who are interested in education seemed to motivate faculty participation in initiative events.

While many participants felt that the initiative complemented other teaching improvement efforts, some participants also expressed confusion/exhaustion with respect to the numerous available tools for teaching improvement. Talking about how the initiative had a synergy with other instructional improvement efforts, Charlie stated:

[T] here's been a lot of publicity around our really wonderful teachers and our [evidence-based instructional practices] and all that stuff and I think that's synergistic with some of the other things happening on campus. I think there is change happening across our campus and I think there is big chunks of it that are related to the way that [the initiative] has happened.

That said, Charlie also expressed exhaustion from numerous opportunities to meet with others around teaching improvements:

...maybe I just get involved with too many things, but there have been so many initiatives at [this institution] recently, which is really wonderful, but I feel like they're all like pieces I feel like should be 
tied together and hasn't yet been done, at least in my mind, and that may be some of the like what the research team of the [initiative] is working on, but that hasn't been transparent to the faculty part of that team. So for me I feel like the institution could use a plan that allows them to see here's all these initiatives and how they relate to each other and here's where we should now go onto target, because we can't just keep targeting large, lower division, high enrollment courses in every initiative that we have, because I can only do so many things. That's how I feel today.

An example of confusion comes from Bowie, who explained that some of the instructional improvement events "blur together, especially because there's so many of the same faces at many of these events." These excerpts suggest that while the initiative was generally thought of as a tool that complemented other instructional improvement efforts, numerous opportunities may have made it challenging for some faculty to want to engage in yet another initiative or differentiate their participation from other events with the same attendees.

Participants also suggested that the initiative may have changed some of the rules influencing engagement in teaching-related conversations. Specifically, a few participants suggested the initiative added value to STEM teaching and learning, like Avery who explained:

I think the strong point about [the initiative] was bringing people together from different disciplines, have them talk to each other and realizing, hey, we have a common goal and we can look to each other for support, even if sometimes, say chairs, might find it strange or why do it, it's working, so you can really help each other to value what you're doing that's the right thing to do, even though someone at the administrative level may say well we need to save money and so we shouldn't do it. So you get some support and say yes, this is important, we have to spend the money on it. It's always about money of course at some point, but it helps the students learn. So I think to me ... It's a very important thing the community building part that [the initiative] has done.

However, Ellery commented on how faculty might feel uncomfortable exposing a lack of teaching-related knowledge, explaining that the initiative "had a bit of a chilling effect on some conversations because some people are uncomfortable with it or they have criticisms of it." Ellery said they felt like their unit was interested in talking more about "stuff" like "students and teaching and mentoring and some research and stuff," but that "[n] one of these people go to any of the [initiative] stuff." They speculated:

I'm not sure why that is, but my guess is just a real vulnerability and sensitivity to judgment, that for whatever reason, because of parallel positions or just I'm an amazing person, they don't feel judged in that smaller circle, so there's energy and motivation to engage. For some reason it doesn't transfer over to the large-scale thing. The only sense I can make of that is there's an association of uncomfortable exposure and judgment.

Ellery points to an unease at exposing a lack of teaching-related knowledge as a potential inhibitor to faculty participation in initiative-related events.

Participants also suggested the initiative helped community members meet others and consider, or make, teaching improvements. For example, Charlie explained, " $[\mathrm{M}]$ uch like the way science works, it's like by having a community of collaborative individuals we end up being more creative by the end of it, so I think it's an incredibly good way to do it." Avery noticed people in their unit making teaching improvements, inspired by a practitioner inquiry fellow's success:

If we look at our [unit] again, we want to look at our [unit] again, the one instructor who flipped his classroom, definitely there was a lot that was driven by what [the initiative] was doing and a lot of people that are much more traditional you can kind of see them listening, picking up things, and slowly moving in the same direction because they see how it works, you get this consensus which is slowly built and moving on there.

To these participants, the initiative brought faculty together so they could explore, implement, and, as Avery notes, inspire others to consider instructional improvements.

Even still, some participants suggested that the initiative did not influence, or had minimal influence on, some community members' conversations around teaching-related topics or teaching-related improvements. For example, Charlie explained, "I know people who think that's [learning about teaching in a community of collaborative individuals] not how they want to get engaged with this kind of stuff. So I don't know if that would engage everyone. It certainly is a great way to engage me." Alexis similarly confessed to knowing faculty who had attended an initiative-related event and "walked away and they're like, 'I don't feel like, I didn't walk away with one thing that now I know is going to make me a better teacher, so what did I get out of it." 
Dana suggested that the initiative could not influence teaching-related conversations in their unit because, "I don't teach lower-division [classes in my discipline, so] there isn't much communication about teaching at the [unit-]level and I think that's a big flaw of the [unit]. So because of that we're in this state for various reasons and I don't think the [initiative] is going to fix it." When asked if the initiative had any impact on their interactions around teaching, Dana simply noted they "had not noticed [the initiative] at all." ${ }^{6}$ For some faculty, for various reasons, the initiative did not have an influence on their teaching practices or conversations about teaching.

Last, a few faculty members commented on how the initiative helped them efficiently learn about teaching by providing opportunities to collaborate with colleagues, suggesting that initiative-related opportunities catered to their busy roles as STEM faculty. For example, Blake commented on the efficiency of learning about instructional improvements by talking with colleagues: "I think that I myself and probably lots of people in my position are not going to the literature frequently to look at the next published methodology or whatever, so we're getting a lot of this through interacting with our colleagues." This suggests that making space and time to learn about teaching, amidst busy faculty roles, was a positive aspect of the initiative for some faculty.

\section{How have STEM faculty networks, representing faculty discussions about teaching-related topics, changed over the life of an initiative?}

To illuminate how teaching-related discussion networks changed over the life of an initiative, we used social network analysis to compare the cohesiveness of faculty networks in 2014 and 2017 (Fig. 4). To help us understand and compare network cohesiveness, we calculated four metrics of interconnectedness (density, centralization, diameter, and average path length) as well as the number of in-unit and out-of-unit ties for each participant. Density calculations indicated that the 2014 network contained $5.3 \%$ of the total potential ties and the 2017 network contained $6.2 \%$ of the total potential ties. Although we anticipate density might be most affected by the different network sizes, the densities of the 2014 and 2017 networks ( 0.053 with 58 faculty and 0.062 with 50 faculty, respectively) are very similar. For this reason, we conclude that

\footnotetext{
${ }^{6}$ Although Dane offered similar responses to Dana, not all participants who indicated little to no involvement in the initiative felt like it had no effect. For example, Bowie acknowledged that interactions were "catalyzed by the [initiative]" and explained that they were adapting some pedagogical practices that a colleague, who was involved in the initiative, had implemented. Elliott also commented on observing general instructional improvements at the institution, which they attributed to education research and "the kind of things that [two initiative designers/leaders] do."
}

density has not changed remarkably between the two networks, indicating no change in this dimension of cohesiveness. Next, the centralization was 0.127 in both the 2014 and 2017 networks, indicating no change in the extent ties centralized around any faculty member. Furthermore, the low centralization value indicates that ties were relatively distributed throughout the network, instead of centralized around one faculty member. Last, the diameter and average path length were 17 and 6.522 in 2014 and 9 and 3.96 in 2017, respectively. The 2017 diameter of 9 indicates that all pairs of faculty members were connected by a path with a length no greater than 9 ties and the average of all the paths between faculty pairs was 4 . The decreases in diameter and average path length are also visually evident in Fig. 4, where it is apparent that the path lengths between any two faculty are shorter in 2017 than 2014. This indicates that the extent ties were interconnected increased over time.

We pause here to consider each network's cohesiveness across all four measures. The density and centralization did not significantly change between 2014 and 2017. The diameter and average path length, however, noticeably changed between 2014 and 2017 . These latter metrics suggest that the 2017 network is more cohesive than the 2014 network with respect to path length, since teaching-related social ties more closely connect community members in 2017 than in 2014. This suggests that teaching-related knowledge can be more efficiently shared throughout the community compared to when the initiative first started, since the path lengths between any two faculty are shorter than they were in 2014.

Last, we consider the unit affiliations of with whom participants reported talking in 2014 and 2017 (Table 2). We found that all participants, in 2014 and 2017, reported talking with more faculty in their units than outside of their units. In fact, six participants reported talking only with unit members in 2014 and 2017. Four participants reported talking with more faculty outside of their units in 2017 than in 2014, one participant reported talking with the same number of faculty outside of their unit in 2017 and 2014, and three participants reported talking with fewer faculty outside of their units in 2017 than 2014. This data suggests that although networks became more cohesive in 2017, this cohesiveness was not necessarily due to any obvious changes in discussion partners' unit affiliations.

\section{Discussion}

Education researchers have called for greater opportunities for educators to learn about evidence-based instructional practices in collaboration with others in their institutional communities (Bouwma-Gearhart, 2012a; Henderson, Beach, \& Finkelstein, 2011; National 


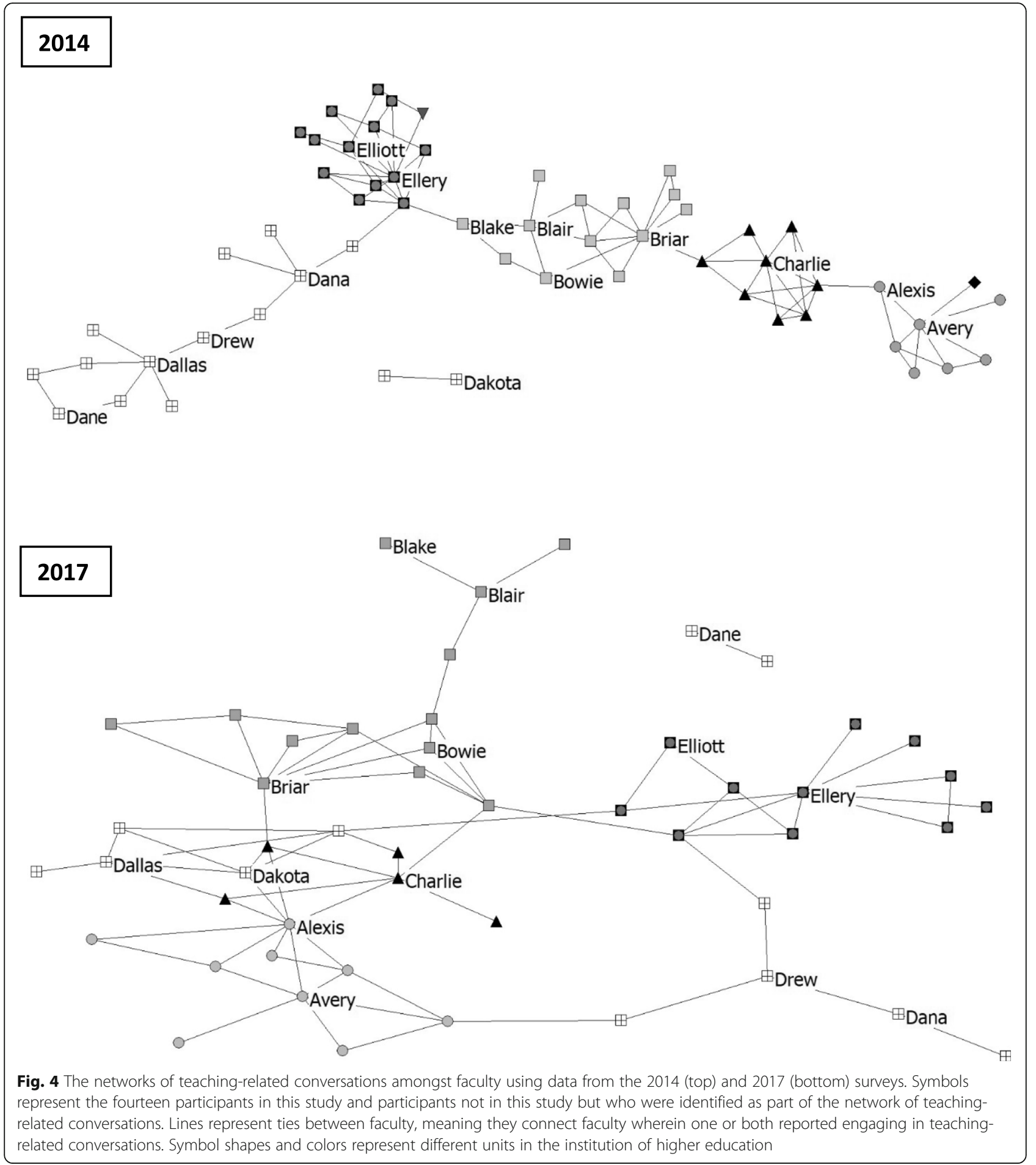

Academies of Sciences, Engineering, and Medicine, 2016). We investigated how STEM faculty engage in teaching-related conversations within the context of an institution of higher education with an ongoing instructional improvement initiative, as well as the extent discussion partners changed over time. Participants communicated various rationales for engaging in teaching-related conversations, suggesting how rules for appropriate behavior, roles and associated duties, and community-related aspects might shape STEM faculty engagement in teaching-related conversations in general and in light of an instructional improvement initiative. We found that faculty were motivated to engage in teaching-related conversations to compare teaching 
Table 2 Number of Community Members with whom Participants Talked about Teaching in 2014 and 2017

\begin{tabular}{|c|c|c|c|c|c|c|}
\hline Participant & $\begin{array}{l}\text { Number of Ties to } \\
\text { Community Members in } \\
\text { Unit (2014) }\end{array}$ & $\begin{array}{l}\text { Number of Ties to } \\
\text { Community Members } \\
\text { Outside Unit (2014) }\end{array}$ & $\begin{array}{l}\text { Total } \\
\text { Ties } \\
(2014) \\
\end{array}$ & $\begin{array}{l}\text { Number of Ties to } \\
\text { Community Members in } \\
\text { Unit (2017) }\end{array}$ & $\begin{array}{l}\text { Number of Ties to } \\
\text { Community Members } \\
\text { Outside Unit (2017) }\end{array}$ & $\begin{array}{l}\text { Total } \\
\text { Ties } \\
(2017)\end{array}$ \\
\hline Avery & 6 & 1 & 7 & 6 & 0 & 6 \\
\hline Alexis & 2 & 1 & 3 & 5 & 4 & 9 \\
\hline Blake & 2 & 1 & 3 & 1 & 0 & 1 \\
\hline Blair & 4 & 0 & 4 & 3 & 0 & 3 \\
\hline Bowie & 3 & 0 & 3 & 3 & 0 & 3 \\
\hline Briar & 8 & 1 & 9 & 7 & 1 & 8 \\
\hline Charlie & 7 & 0 & 7 & 4 & 2 & 6 \\
\hline Dallas & 5 & 0 & 5 & 4 & 1 & 5 \\
\hline Dakota & 1 & 0 & 1 & 3 & 2 & 5 \\
\hline Drew & 2 & 0 & 2 & 3 & 0 & 3 \\
\hline Dana & 4 & 0 & 4 & 2 & 0 & 2 \\
\hline Dane & 2 & 0 & 2 & 1 & 0 & 1 \\
\hline Ellery & 8 & 1 & 9 & 8 & 0 & 8 \\
\hline Elliott & 4 & 0 & 4 & 2 & 0 & 2 \\
\hline
\end{tabular}

practices and find teaching-related support in comfortable and safe conversations and that the initiative helped create an interdisciplinary, teaching-focused community they may have felt they lacked. Some participants even desired more initiative-related events, continued initiative-related events, and more units' involvement in the initiative, further suggesting that the initiative spoke to faculty desires to grow their knowledge of, and connect with, the teaching-interested community at their institution. We also learned that faculty were aware of many different tools they could use (and were using) to engage in teaching-related conversations, including those within STEM units, inside the institution, and outside the institution. Many participants felt the initiative complemented existing teaching/improvement efforts, although some felt confusion or expressed exhaustion with respect to the numerous available tools for teaching improvement.

To illuminate how teaching-related discussion networks changed over the life of an initiative, we used social network analysis to compare the cohesiveness, or interconnectedness, of faculty networks in 2014 (shortly after the initiative was implemented) and 2017 (about three years after the initiative was implemented). Results suggest that the 2017 network was more cohesive than the 2014 network, indicating that teaching-related knowledge could be more efficiently shared throughout the community compared to when the initiative was implemented. We also found that participants, in both 2014 and 2017, talked with more faculty in their units than outside of their units and that most participants experienced different changes in terms of with whom they talked about teaching. However, comparing changes in the unit affiliation of discussion partners showed no noticeable trends representing all faculty (e.g., not all participants reported talking to more discussion partners outside of their unit in 2017 than in 2014).

\section{Salient system tensions potentially inhibiting teaching- related conversations}

We now turn to a discussion of system tensions that might impact teaching-related conversations and propose recommendations for stakeholders.

\section{STEM faculty have autonomy with respect to teaching practices}

Many participants reported great autonomy with how to teach, which may be particularly true for those teaching upper-division/graduate-level courses. This reality may inhibit conversations specifically about teaching practices since there is not a need to discuss, learn, and implement specific pedagogy, such as evidence-based instructional practices. At the same time, some participants reported having little autonomy over what to teach, sometimes due to the need to coordinate courses with other instructors or institutions. This suggests that faculty might be more inclined to have teaching-related conversations when they feel that content needs to be aligned.

We speculate that conversations about teaching practices may also be more effort-intensive since they might necessitate faculty elucidate teaching rationales to explain or justify how they teach. Pedagogical training is likely varied amongst faculty and faculty may have different comfort levels in terms of engaging in conversations about teaching practices, particularly if they perceive 
threats to acknowledging a lack of adequate teachingrelated knowledge. This might be particularly true for faculty whose perception of institution or unit climate, culture, or norms leads them to conclude that teachingrelated conversations are not supported. Thus, talking with community members about aligning course content may be an easier conversation in which to engage STEM faculty since it may not or may limitedly involve discussion about how to teach course content.

This tension provides insight into our social network findings. In both 2017 and 2014, participants reported more discussions with community members within their units than outside of their units and we expect that intra-unit conversations might be focused on aligning content because faculty might have to coordinate curriculum and may be more comfortable having these types of conversations. Similar findings in previous research on the same initiative supports this interpretation: STEM faculty members tend to talk about day-today needs and not necessarily system-level topics that influence teaching practice (Quardokus Fisher, Sitomer, Bouwma-Gearhart, \& Koretsky, 2019).

\section{Community members have varying levels of interest in teaching-related improvements}

Participants reported working in a community where colleagues were diversely interested in teaching-related improvements. Faculty spoke about engaging in teaching-related discussions with community members who were interested in teaching, valued teaching, or wanted to know how to implement teaching improvements. These types of community members, our participants suggested, seemed more approachable for teaching-related conversations. Also, those with a professional position focused on teaching might afford teaching-related conversations: If there are formal expectations that a faculty member's main efforts should be delivering quality teaching to students (e.g., as it might be for fixed-term faculty, faculty specifically coordinating courses, etc.), a faculty member may be more inclined to seek out and participate in teaching-related conversations. Conversely, some members in the community were perceived as only willing to lecture, possessing little teaching-related knowledge and, at times, unable to engage in civil conversations about teaching improvements. These types of community members, our participants suggested, generally inhibited teaching-related conversations.

Our 2014 and 2017 networks show with whom STEM faculty talk about teaching-related topics and may identify community members who generally welcome teaching-related conversations. Our 2014 and 2017 social network analyses (via decreases in average path length and diameter over time) suggest enhanced community interconnectedness and, thus, enhanced ability to expediently share teaching-related information among involved faculty. Considering these findings and the many participant excerpts on how the initiative helped create an interdisciplinary, teaching-focused community, we believe the initiative, amongst a variety of other instructional improvement efforts, helped faculty who wanted to engage in teaching-related conversations gain a better awareness of with whom they could connect.

\section{Varying levels of support are typically given to STEM faculty to engage in teaching-related conversations}

Participants had varied perceptions about the amount of support they felt to engage in teaching-related conversations, which likely influences engagement in teachingrelated conversations. In some instances, participants generally indicated a 'culture' in academia affecting teaching-related conversations, although specific aspects of culture were not often specified. Others indicated more detailed and localized 'climate' or 'norms' (e.g., administrators supporting teaching-related conversations) that they felt influenced conversations. This nuance is worth considering because factors associated with climate (e.g., a current department chair) are potentially quicker and easier to change than those comprising organizational culture (e.g., faculty promotion and tenure-related norms) (Walter et al., 2014).

Relatedly, participants suggested that administrative support for teaching improvements and/or teachingrelated conversations could help foster teaching discussions. This highlights the powerful role administrators play, in terms of supporting faculty engagement in teaching-related conversations. Our data suggest that if administrators promoted/implemented policies, or even informally supported educators' engagement in teaching-related conversations and instructional improvement efforts (e.g., a department head commending faculty efforts to incorporate evidence-based instructional practices during a department meeting), faculty might be more inclined to engage in teaching-related conversations.

Furthermore, some faculty perceived working in roles that did not support teaching-related conversations. For example, participants reported having too little time to spend on teaching, suggesting that other aspects of their roles might be privileged over teaching. Also, some faculty suggested that there may be a perception that teaching-related improvements and/or engaging in teaching-related conversations were simply not a part of, or not an important part of, their roles. Last, one faculty member commented on how late course assignments inhibited teaching-related conversations, suggesting that simply notifying faculty about teaching assignments 
earlier could support engagement in teaching-related conversations.

When we consider these findings in light of the social networks, we note how density and centralization did not change between 2014 and 2017. If density increased in 2017, it might suggest faculty increased their numbers of discussion partners. Little change in density might be likely because, as our interviewees indicated, STEM faculty are busy or prioritize other responsibilities, and thus might be limited in the number of community members with whom they connect. Additionally, STEM faculty might feel inhibited to increase their teaching-related discussion partners because some may believe that engaging in teaching-related improvements is unsupported by their roles and/or the culture/climate of their workplace.

\section{STEM faculty may lack inclusive and judgment-free spaces to talk about teaching}

A couple of participants indicated that not all opportunities to talk about teaching were inclusive and judgmentfree. One of our participants hinted at feeling like an outsider, since they identify with a gender underrepresented in STEM/academia, explaining that this dissuaded them from contributing to conversations about teaching practices and experiences. Perhaps this should not be surprising, as previous research has noted that educators with identities underrepresented in STEM often face discrimination or hostile work environments (National Academies of Sciences, Mathematics, and Engineering, 2018). Also, one participant suggested that STEM faculty might want to hide teaching-related issues or a lack of teaching experience. This participant further speculated that this might keep some community members from participating in the initiative. These perspectives suggest 'rules' inhibiting all community members from participating in teaching-related conversations and 'rules' describing the degree they can openly share teaching knowledge with community members.

\section{Recommendations for stakeholders, towards fostering faculty communication around instruction}

Looking across the results of our research questions and tensions potentially inhibiting teaching-related conversations helps us suggest recommendations for those designing and implementing instructional improvement initiatives as well as unit leaders and STEM faculty. This is particularly true for those attempting to foster instructional improvements via communities, where faculty can collaboratively share and learn about teaching practices and instructional improvements.

\section{Uncover and leverage faculty members' interests in diverse} teaching-related topics

Participants indicated that faculty are busy and have autonomy in terms of deciding how to teach, which might be a barrier to engaging them in instructional improvement work (including via faculty communities). Given these considerations, it is perhaps of great importance that initiative leaders, designers, and administrators cater to faculty members' teaching needs and interests, which our participants indicated are plentiful and diverse, when designing and implementing instructional improvement opportunities (as also noted in Bouwma-Gearhart, 2012b; Bouwma-Gearhart, Lenz, \& Ivanovitch, 2019; Oleson \& Hora, 2014). If faculty view learning communities as places where they can converse with others around teaching-related topics that are useful to their contexts and meet their interests, they might be more likely to engage. Additionally, STEM faculty might consider forming their own learning communities with others who are drawn to learning and discussing the same teaching topics.

Indeed, encouraging faculty to bring their teaching experiences and expertise to conversations can be important in helping them think about how to improve teaching. Specifically, scholars have pointed to the importance of helping STEM faculty realize a "dissatisfaction with the teaching and learning goals established for students, beliefs about students and how they learn, and beliefs about the effectiveness of instructional practices" (Gess- Newsome, Southerland, Johnson, \& Woodbury, 2003 , p. $762-763)$. Faculty might develop such awareness when they make explicit their teaching-related notions and broaden their knowledge of teaching through conversations with other educators. As we discuss below, it is important to elicit and respond to teaching-related experiences, beliefs, and interests with a sense of curiosity and non-judgement to help faculty comfortably and candidly share teaching knowledge.

\section{Acknowledge that faculty may already be involved in opportunities where they engage with others around teaching-related topics}

Our participants indicated faculty were involved in a diverse array of instructional improvement opportunities where they might engage in teaching-related conversations, including those within their units, in the institution, and outside of the institution. They also spoke of how the initiative contributed to the momentum of instructional improvement efforts at the institution, further suggesting that participants perceived many instructional improvements underway. One participant even indicated feeling exhausted per being involved in so many improvement opportunities and some participants expressed confusion about what improvement 
opportunities were part of this specific initiative. Given these findings, we assert that it is important for initiative leaders and designers, particularly those creating and fostering faculty communities, to consider synergizing with other teaching-related improvement efforts. For example, instructional improvement efforts might be coordinated so strategies target different populations of faculty (e.g., fixed-term, tenure-track, etc.) or different teaching foci (e.g., lower-division, upper-division, graduate, etc.).

Calling on initiative designers and implementers to operate with intentionality and knowledge of the institutional system during initiative design and implementation has also been suggested by previous researchers (Bouwma-Gearhart, Ivanovitch, Aster, \& Bouwma, 2018; Bouwma-Gearhart \& Collins, 2015; Henderson et al., 2011). Our findings specifically suggest that one part of the institutional system to consider is the larger landscape of initiatives and professional development efforts available, wherein faculty might already invest parts of their limited time in teaching-related conversations. Administrators, instructional improvement designers and leaders, and STEM faculty should consider exchanging knowledge of these opportunities towards guiding additional efforts.

Relatedly, participants talked about wanting more regulations or policies supporting quality teaching, such as making explicit the institution's vision for instructional improvements. Explicit regulations or policies regarding teaching quality could help those creating and implementing instructional improvement initiatives focus efforts around organizational requirements. This would also help faculty see that instructional improvements are valued by the organization and perhaps increase motivation to engage in instructional improvements.

\section{Create spaces where faculty can talk with community members about teaching-related topics}

Many participants spoke about how engaging in teaching-related conversations helped them compare teaching practices and find teaching-related support. Additionally, many participants spoke about how they felt the initiative provided important opportunities for them to engage in a faculty community composed of members from across the STEM disciplines. This finding can be related to the decrease in network average path length and diameter, which suggests that faculty were more connected than before. Although we cannot directly link this finding back to the initiative, interview excerpts suggest the initiative was an important part of the STEM instructional improvement efforts that helped faculty meet and exchange teaching-related knowledge with community members across the institution. Our participants suggest that faculty want to have opportunities to connect with others about teaching-related topics and would be interested in engaging in these opportunities.

In fact, several faculty desired more initiative-related events and opportunities, with more units involved. The specific desire to talk with community members outside of one's unit may be a big draw for faculty on the part of their engagement in multidisciplinary, initiative-fostered communities. Relatedly, research has noted that creating opportunities for faculty to engage with others around teaching-related topics may be particularly important for faculty who feel departmentally isolated in terms of their interest in teaching-related topics. Participating in faculty communities can supply faculty with "energy, enthusiasm, encouragement, and affirmation" (Kezar et al., 2017, p. 253) that they may not get in their units. This suggests that initiative leaders and designers consider ways to build, sustain, and grow interdisciplinary faculty communities where educators can meet with STEM faculty across the institution who are interested in collaboratively learning teaching-related topics.

Some participants also offered statements about how initiative-related communities had either contributed to their or others' effective uptake of novel pedagogical practices towards improving student learning. These results mirror those found in Gehrke and Kezar (2016), who found that $70 \%$ of their study participants reported altering practices while involved in large-scale STEM communities. Engaging educators in faculty communities, where they might collaboratively learn instructional improvements, can be an effective way to improve postsecondary STEM education.

Also, as a few of our participants noted, engaging in teaching-related conversions could be an efficient way to learn about teaching, especially for busy faculty who do not have extra time to consult the literature. Marketing faculty communities as a way to efficiently learn about evidence-based instructional practices could be a useful way for initiative leaders, designers, and administrators to engage busy faculty in events. If faculty believe that communities can help them address their teaching needs and help them explore their teaching-related interests, they might be more inclined to participate.

Many participants' discussion partners changed in 2014 and 2017, in terms of whether those partners were within the participants' units or outside their units. Social network analysis, specifically diameter and average path length, showed that the networks changed in such a way that teaching-related information could travel through the community by 'going through' fewer people. This suggests that, as interested faculty participate in opportunities with other educators, the overall network of teaching-related discussions might increase in cohesiveness through decreases in diameter and average path length. In other words, with an overall shift of the network to 
conversations between units, teaching-related knowledge can be more expediently communicated across the institution.

\section{Create spaces for sharing that are inclusive and safe, towards fostering faculty participation in teaching-related conversations}

Our results also suggest that conversational opportunities for STEM faculty, where they might share and learn about teaching, must be inclusive and safe. This means any faculty member can air genuine teaching concerns to a respectful and helpful audience. Therefore, initiative leaders, designers, administrators, and STEM faculty constructing opportunities for teaching-related conversations should consider communicating explicit norms for sharing and reception. For example, one norm may be approaching others' comments and experiences with curiosity, not judgment. This may help faculty feel more comfortable sharing genuine teaching-related experiences and knowledge.

Another way to help faculty feel comfortable is to explicitly acknowledge the difficulty of teaching as well the norms for pedagogical training and support provided to some STEM faculty throughout their graduate student years and employment. The reality that pedagogical training is varied among STEM faculty is one to handle delicately so as not to cause push-back that might impede teaching improvement efforts. Faculty members who perceive a lack of teaching skills and knowledge as a professional failing, or perceive others judging these as failings, may be less motivated to engage in teaching improvement efforts. Like others (Bouwma-Gearhart, 2012a), we suggest initiative leaders, designers, and administrators acknowledge and address this norm in teaching-related communities. If faculty know that teaching requires learning, is difficult, and that struggling is part of an educator's growth, they might feel more comfortable admitting to and discussing teaching difficulties. Such explicit acknowledgments help serve as bases for safe professional development spaces for STEM faculty at institutions (Bouwma-Gearhart, 2012a) as well as STEM faculty engaged in large-scale reform efforts (Kezar et al., 2017).

\section{Develop the administrative support that may be necessary to help foster and sustain opportunities for faculty to talk about teaching}

Our participants suggested the importance of administrative endorsement of improvement efforts and teaching-related conversations. This suggests that getting buy-in from administrators, who have more powerful roles, is very important to foster and sustain instructional improvement opportunities for faculty to talk with others about teaching. This result echoes that found in previous studies, which have suggested the importance of engaging upper-level administrators in instructional improvement initiatives (Callahan, Pyke, Shadle, \& Landrum, 2014; Gehrke \& Kezar, 2016).

Specifically, administrators can help foster instructional improvement initiatives by offering support and recognition to STEM faculty working collaboratively to learn about teaching. This support might manifest as modifying environments and structures to allow (and encourage) time for faculty to engage in teaching-related conversations and teaching-related improvements. For example, administrators could explicitly clarify (e.g., include in position descriptions) that time participating in teaching-related conversations (e.g., departmental course meetings) is expected as part of faculty members' duties. This would likely necessitate alleviating faculty time from other tasks, since our participants also lamented being too busy to spend time on teaching. Another example is unit administrators working with instructional improvement leaders and designers to create required pedagogical professional development opportunities for new faculty. Through such administrative support, STEM faculty might feel more inclined to participate in teaching-related discussions and consider instructional improvements.

\section{Studying STEM faculty experiences in instructional improvement efforts: reflections on combining social network and interview analysis}

We close our discussion with brief but critical thought about using social network and interview analysis to understand how STEM faculty engage in teachingrelated conversations. Analysis of social networks illuminated how the teaching-related connections STEM faculty had with discussion partners created a larger network, and how this network's cohesiveness changed over time. However, social network analysis did not illuminate STEM faculty members' rationales for engaging in teaching-related conversations. To understand this aspect, we analyzed interviews with STEM faculty. We argue that this combination of methods provided a more robust, yet effort-intensive, picture of how STEM faculty engage in teaching-related conversations at an institution of higher education with an ongoing instructional improvement initiative. If we had limited our study to social network analysis, we likely would have observed changes in cohesiveness due to path length but would not have been able to interpret this change. Our interviews help uncover the context STEM faculty work in, showing a diverse community with variable motivations and opportunities to participate in teaching-related conversations. Conversely, if we had only used interview data, we may not have known the extent the network of discussion partners changed over time. 
Participants suggested they wanted to engage in teaching-related conversations to compare teaching practices and find support in comfortable and safe conversations. Our study suggests that the initiative helped them do this, via creating spaces for an interdisciplinary community of faculty to come together to talk about teaching-related topics. While it may not have influenced all faculty members' engagement in teachingrelated conversations, those who participated in initiative-related events largely saw the initiative as very impactful towards adding value to STEM teaching and learning and helping community members meet others to consider and/or make teaching improvements. Furthermore, the network representing discussion partners (or, with whom faculty talked about teaching) grew more interconnected over the life of the initiative. This suggests that teaching-related knowledge can be more expediently distributed throughout the network. We suggest that combining social network analysis with interviews is a fruitful, albeit time-intensive method for the robust study of how STEM faculty engage in teaching-related conversations.

\section{Conclusion}

Our study explored STEM faculty engagement in teaching-related conversations at an institution of higher education with an ongoing teaching improvement initiative. We found tensions that may influence faculty engagement in teaching-related conversations and discussed these results in light of faculty members' discussion networks. We suggest initiative leaders and designers consider creating spaces where faculty can talk with colleagues, across the institution of higher education, about teaching. Discussions about teaching-related topics should be inclusive and safe to help faculty feel like they can air real teaching-related concerns and insights to respectful and responsive listeners. Our study also shows that STEM faculty have a diverse-array of teaching-related interests, which suggests it is particularly important for stakeholders hoping to engage faculty in teaching-related conversations to build off faculty interests and knowledge. Those hoping to foster new faculty communities might also consider working with members across the institution, such as administrators, staff, and STEM faculty, to understand the diverse instructional improvement opportunities STEM faculty may already take part in and focus instructional improvement efforts in areas lacking support. Our study echoes the results of prior research by drawing attention to the importance of administrative support towards fostering and sustaining opportunities for faculty to talk with others about teaching. This study contributes to the important and growing body of research on how to meaningfully engage STEM faculty in instructional improvement opportunities, towards enhancing undergraduate STEM education.

\section{Acknowledgements}

Not applicable.

\section{Authors' contributions}

EA helped design the study, analyze and interpret data, and write the manuscript. JBG helped design the study, interpret data, and write the manuscript. KQF helped design the study, analyze and interpret the data, and write the manuscript. All authors read and approved the final manuscript.

\section{Funding}

Financial support was provided by the National Science Foundation grant DUE 1347817. Any opinions, findings, and conclusions or recommendations expressed in this material are those of the authors and do not necessarily reflect the views of the National Science Foundation.

\section{Availability of data and materials}

The data that support the findings of this study are available upon request from the corresponding author, EMA. The data are not publicly available due to containing information that could compromise research participant privacy/consent.

\section{Declarations}

Ethics approval and consent to participate

Approval for this study was obtained by the Oregon State University Institutional Review Board.

Consent for publication

Not applicable.

\section{Competing interests}

The authors declare that they have no competing interests.

\section{Author details}

${ }^{1}$ Colorado State University, Fort Collins, USA. ${ }^{2}$ Oregon State Univesity, Corvallis, USA. ${ }^{3}$ Florida International University, Miami, USA.

Received: 13 July 2021 Accepted: 8 November 2021

Published online: 27 November 2021

\section{References}

Auerbach, C., \& Silverstein, L. B. (2003). Qualitative data: An introduction to coding and analysis. New York, NY: New York University Press.

Bouwma-Gearhart, J. (2008). Teaching professional development of science and engineering professors at a research-extensive university: Motivations, meaningfulness, obstacles, and effects (Order No. 3327743). Available from ProQuest Dissertations \& Theses Global. (304450320). Retrieved from https:// ezproxy2.library.colostate.edu/login?url=https://www.proquest.com/disserta tions-theses/teachingprofessional-development-science/docview/304450320/ se-2? accountid $=10223$.

Bouwma-Gearhart, J. (2012a). Engaging STEM faculty while attending to professional realities: An exploration of successful postsecondary STEM education reform at five SMTI institutions. Washington: Association of Public and Landgrant Universities.

Bouwma-Gearhart, J. (2012b). Research university STEM faculty members' motivation to engage in teaching professional development: Building the choir through an appeal to extrinsic motivation and ego. Journal of Science Education and Technology, 21(5), 558-579. https://doi.org/10.1007/s10956011-9346-8.

Bouwma-Gearhart, J. (2012c). Science faculty improving teaching practice: Identifying needs and finding meaningful professional development. International Journal of Teaching and Learning in Higher Education, 24(2), 180-188.

Bouwma-Gearhart, J., \& Adumat, S. (2011). Fostering successful interdisciplinary postsecondary faculty collaborations. International Journal of University Teaching and Faculty Development, 2(3), 207. 
Bouwma-Gearhart, J., \& Collins, J. (2015). What we know about data-driven decision making in higher education: Informing educational policy and practice. Presented at the 19th International Academic Conference, Florence, Italy, p. 89-131.

Bouwma-Gearhart, J., Lenz, A., \& Ivanovitch, J. (2019). The interplay of postsecondary science educators' problems of practice and competencies: Informing better intervention designs. Journal of Biological Education, 53(4), 365-377.

Bouwma-Gearhart, J., Perry, K., \& Presley, J. B. (2012). Improving postsecondary STEM education: Strategies for successful collaboration and brokering across disciplinary paradigms. Issue 4. Washington, D.C.: Association of Public and Land-Grant Universities.

Bouwma-Gearhart, J., Perry, K., \& Presley, J. B. (2014). Improving postsecondary STEM education: Strategies for successful interdisciplinary collaborations and brokering engagement with education research and theory. The Journal of College Science Teaching, 44(1), 40-47. https://doi. org/10.2505/4/jcst14_044_01 40.

Bouwma-Gearhart, J., Sitomer, A., Quardokus-Fisher, S., Smith, C., \& Koretsky, M. (2016). Studying organizational change: Rigorous attention to complex systems via a multi-theoretical research model. Presented at the 2016 American Society for Engineering Education Annual Conference \& Exposition. New Orleans, LA.

Bouwma-Gearhart, J. L., Ivanovitch, J. D., Aster, E. M., \& Bouwma, A. M. (2018a). Exploring postsecondary biology educators' planning for teaching to advance meaningful education improvement initiatives. CBE-Life Sciences Education, 17(3), 1-12. https://doi.org/10.1187/cbe.17-06-0101.

Callahan, J., Pyke, P., Shadle, S., \& Landrum, R.E. (2014). Creating a STEM identity: Investment with return. Proceedings of the 121 American Society for Engineering Education Annual Conference \& Exposition, IN, AC2014-10733.

Carnegie Classification of Institutions of Higher Education (n.d.). About Carnegie Classification. Retrieved from https://carnegieclassifications.iu.edu/.

Coldron, J., \& Smith, R. (1999). Active location in teachers' construction of their professional identities. J. Curriculum Stud., 31(6), 711-726. https://doi.org/10.1 080/002202799182954.

Creswell, J. W. (2014). Qualitative inquiry and research design. Thousand Oaks, CA: SAGE Publications, I

Engeström, Y. (2009). Expansive learning: Toward an activity-theoretical reconceptualization. In K. Illeris (Ed.), Contemporary theories of learning: Learning theorists - In their own words. Routledge.

Engeström, Y. (2014). Learning by expanding. Cambridge University Press. https:// doi.org/10.1017/CBO9781139814744.

Foot, K. A. (2014). Cultural-historical activity theory: Exploring a theory to inform practice and research. Journal of Human Behavior in the Social Environment, 24(3), 329-347. https://doi.org/10.1080/10911359.2013.831011.

Gast, I., Schildkamp, K., \& van der Veen, J. T. (2017). Team-based professional development interventions in higher education: A systematic review. Review of Educational Research, 87(4), 736-767. https://doi.org/10.3102/003465431 7704306.

Gehrke, S., \& Kezar, A. (2016). STEM reform outcomes through communities of transformation. Change, 48(1), 30-38. https://doi.org/10.1080/00091383.201 6.1121084.

Gess-Newsome, J., Southerland, S. A., Johnston, A., \& Woodbury, S. (2003). Educational reform, personal practical theories, and dissatisfaction: The anatomy of change in college science teaching. American Educational Research Journal, 40(3), 731-767. https://doi.org/10.3102/00028312040003731.

Henderson, C., Beach, A., \& Finkelstein, N. (2011). Facilitating change in undergraduate STEM instructional practices: An analytic review of the literature. Journal of Research in Science Teaching, 48(8), 952-984. https://doi. org/10.1002/tea.20439.

Henderson, C., Rasmussen, C., Knaub, A., Apkarian, N., Quardokus Fisher, K., \& Daly, A. (Eds.) (2018). Researching and enacting change in postsecondary education: Leveraging instructors' social networks. New York: Routledge. https://doi.org/1 $0.4324 / 9780429442803$.

Hollstein, B. (2011). Qualitative approaches. In: J. Scott \& P. J. Carrington (Eds.), Sage Handbook of Social Network Analysis (pp. 404-416). London: SAGE Publications Ltd.

Kezar, A., Gehrke, S., \& Bernstein-Sierra, S. (2017). Designing for success in STEM communities of practice: Philosophy and personal interactions. The Review of Higher Education, 40(2), 217-244. https://doi.org/10.1353/rhe.2017.0002.

Knaub, A. V., Henderson, C., \& Quardokus Fisher, K. (2018). Finding the leaders: An examination of social network analysis and leadership identification in STEM education change. International Journal of STEM Education, 5(26), 1-14. https://doi.org/10.1186/s40594-018-0124-5.

Leont'ev, A. N. (1981). Problems of the development of the mind. Moscow: Progress.

National Academies of Sciences, Engineering, and Medicine (2016). Barriers and opportunities for 2-year and 4-year STEM degrees: Systemic change to support students' diverse pathways. Washington: The National Academies Press.

National Academies of Sciences, Engineering, and Medicine (2018). Indicators formonitoring undergraduate STEM education. Washington: The National Academies Press.

Oleson, A., \& Hora, M. T. (2014). Teaching the way they were taught? Revisiting the sources of teaching knowledge and the role of prior experiences in shaping faculty teaching practices. Higher Education, 68(1), 29-45. https://doi. org/10.1007/s10734-013-9678-9.

Prell, C. (2012). Social network analysis: History, theory, \& methodology. Thousand Oaks, CA: Sage Publications, Inc.

Quardokus Fisher, K., Sitomer, A., Bouwma-Gearhart, J., \& Koretsky, K. (2019). Using social network analysis to develop relational expertise for an instructional change initiative. International journal of STEM education. 6, 6(1). https://doi. org/10.1186/s40594-019-0172-5.

Quardokus, K., \& Henderson, C. (2015). Promoting instructional change: Using social network analysis to understand the informal structure of academic departments. Higher Education, 70(3), 315-335. https://doi.org/10.1007/s1 0734-014-9831-0.

Walter, E., Beach, A., Henderson, C., Williams, C. (2014). Describing instructional practice and climate: two new instruments. Paper presented at the Transforming Institutions: 21st Century Undergraduate STEM Education Conference, held 24 October 2014, in Indianapolis, IN.

Wasserman, S., \& Faust, K. (1994). Social network analysis: Methods and applications. New York: Cambridge University Press. https://doi.org/10.1017/ CBO9780511815478.

Wright, M. (2008). Always at odds: Creating alignment between faculty and administration values. Albany: Sate University of New York Press.

\section{Publisher's Note}

Springer Nature remains neutral with regard to jurisdictional claims in published maps and institutional affiliations.

\section{Submit your manuscript to a SpringerOpen ${ }^{\circ}$ journal and benefit from:}

- Convenient online submission

- Rigorous peer review

- Open access: articles freely available online

High visibility within the field

- Retaining the copyright to your article

Submit your next manuscript at $\boldsymbol{\nabla}$ springeropen.com 